\title{
Constructive And Spatial Structure Of Muslim Architecture Of The Sunni Mosques Of Jordan
}

\begin{abstract}
Ali Shurman
Abstract. In this article the author has reviewed the constructive and spatial structure of Muslim architecture of the mosques of Sunnis in Jordan. In the article the author provides a distinctive Distinctive architectural features of mosques of the Sunnis, considered the mosque of Aqaba, which is located in the main street of Aqaba, near the Rings of Khaya. Summarizing the archival research, as well as data on the extant mosques, the author of the article concluded that on the territory of Jordan volumetric-spatial decision of mosques were presented in three types: with a minaret on the roof; with a minaret above the entrance; with the adjacent volume of the minaret.
\end{abstract}

Key words: Aqaba, the architectural ensemble of the mosque of Jordan, the Sunnis, the spatial structure of Muslim architecture.

Суннизм - Доминирующая Ветвь Ислама. "Сунна" Объясняет Священную Книгу Мусульман Коран - И Дополняет Ее. Потому Традиционные Последователи Ислама Считают Следование "Сунне" Главным Содержанием Жизни Каждого Истинного Мусульманина. Причем Речь Часто Идет О Буквальном Восприятии Предписаний Священной Книги, Без Каких Либо Модификаций.

Мечети Стали Местом, Где Собираются Люди, Желающие Совершить Ибадат (Служение), Где Они Ведут Различные Беседы И Слушают Речи Религиозных Лидеров [3, С. 35]. В Наши Дни Мечети Используются Только Для Проведения Служений, Однако Раньше Они Выполняли Различные Функции. Поэтому Для Мусульман, Мечети Занимают Центральное Место В Жизни. Около 95\% Населения Иордании Мусульмане-Сунниты.

Отличительной Архитектурной Особенностью Мечети Суннитов Свидетельствуют Башни В Виде Пики. Мечети Были Прямоугольными, Гумбаз Размещался Прямо Над Молельным Залом. Симметричное Размещение Минарета Относительно Продольной Оси Здания Сближало С Композицией, Распространенной В Исламской Архитектуре. Однако Восточные Черты (Декор Фриза, Завершение Оконных И Дверных Проемов, Декоративное Решение Входного Портала), Заложенные В Каждом Варианте Мечети, Сохранили Специфичную Исламскую Образность (Рис. 1).

Основной Прямоугольный В Плане Объем Молельного Зала Был Разделен На Три Части. Центральная Часть Возвышалась Над Остальными, На Ней Покоился Восьмигранник, Увенчанный Гумбазом. Две Другие Части Основного Объема Завершались Скатной Крышей. Прямоугольный Объем Михраба (Алтарной Части), Завершенный Скатной Крышей, Примыкал К Основной Части С ЮгоЗападной Стороны. Мечеть Имела Один Вход Прямоугольного Очертания С Северо-Восточной Стороны. На Северо-Западном И Юго-Восточном Фасадах Центральной Части Здания Располагались По Три Соединенных Окна, Освещающих Молельный Зал [2, С. 12]. Окна Прямоугольной Формы, Различны По Высоте (Центральное Из Них Выше) И Украшены Деревянными Наличниками. Две Другие Части Основного Объема Здания Имели По Одному Окну. На Юго-Западной Стороне Михраба Также Было Расположено Прямоугольное Окно, Обрамленное Наличником. Минарет Был Разделен На Два Уровня Деревянным Балконом, С Которого Муэдзин Читал Азан - Призыв К Обязательной Молитве. Как Правило, Башня Минарета Имела Три Окна - По Одному На Каждом Из Уровней. 


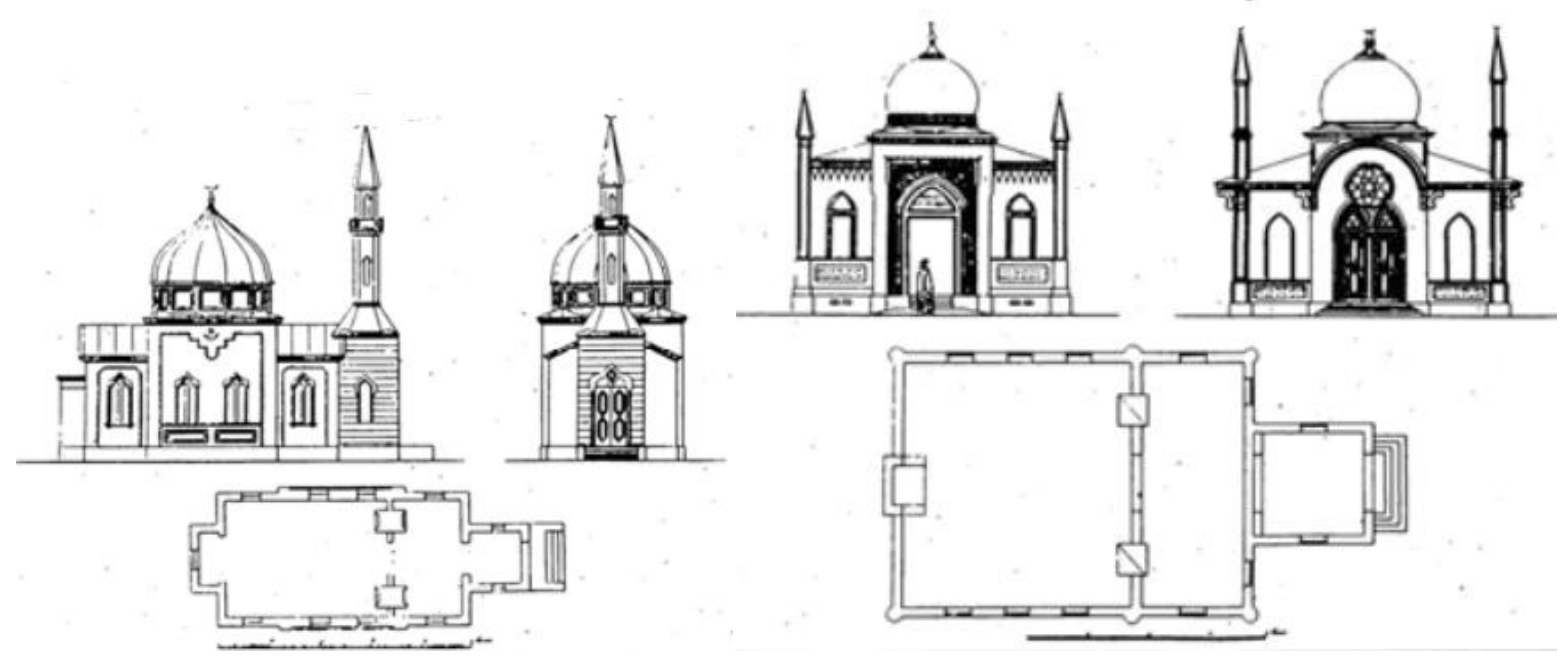

Рис. 1 - Конструктивная И Объемно-Пространственная Структура Мусульманской Архитектуры Мечетей Суннитов

Акаба Один Из Самых Динамично Развивающихся Городов Иордании. По Темпам Строительства Жилья И Других Объектов Он Уступает Лишь Столице Страны. Большинство Мечетей Акабы Построены В Конце XX Начале XXI Века. На Это Время Приходится Строительство Порта Акаба Крупнейшего В Красном Море, Поэтому Одновременно С Портом В Городе Выросли Сотни Домов И Подобающая Им Инфраструктура.

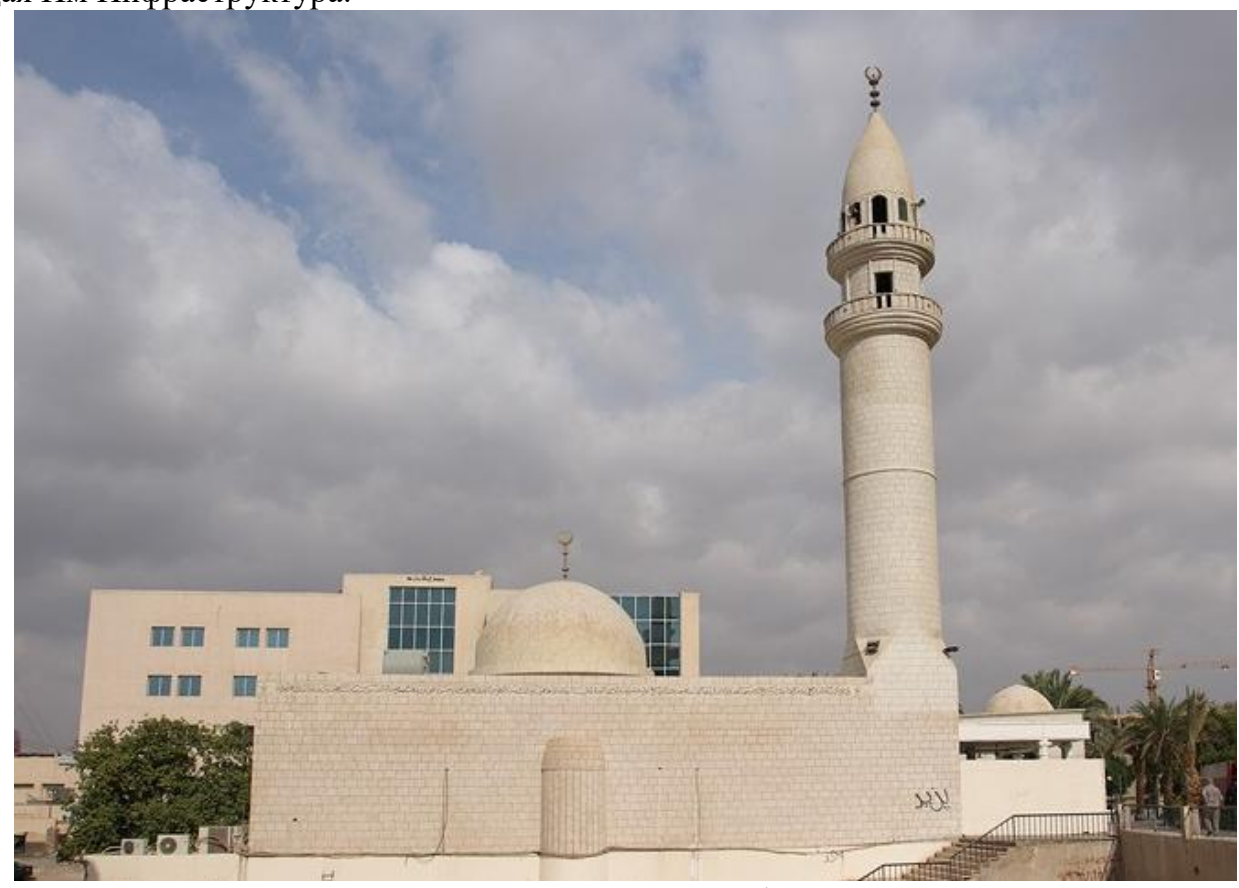

Рис. 2 - Мечеть Акабы

Мечеть Акабы Расположена На Главном Проспекте Акабы, Возле Кольца Хайа. Сравнительно Небольшие Размеры Одной Из Центральных Мечетей Города Объясняются Высокой Сейсмической Опасностью Региона, В Котором Находится Акаба.

Мечеть Квадратная В Плане, Имеет Размеры 19 Х 19 Метров. Всё Внутреннее Пространство Занимает Большой Молитвенный Зал, Над Которым Находится Небольшой Купол Диаметром 7 Метров. Благодаря Куполу Внутри Здания Достигается Хорошая Акустика. Мечеть Имеет 1 Минарет, Его Высота 25 Метров [6, С. 15].

Новый Архитектурный Язык Был И До Сих Пор Разрабатывает Различные Проекты, Методики И Подходы. Начиная Такой Подход, Был Конкурс На Лучший Проект Мечети Короля Абдаллы Аль- 
Абдали; Многие Дизайнеры Приняли Участие, Большинство Из Них Были Местными Жителями, И Некоторые В Сотрудничестве С Иностранными Архитекторами, Которые Работали В Иорданских Фирм. В Результате Первое Место Присуждено Совместной Команде, Строительству И Надзору Взяли Местные Архитектурные Бюро. Кроме Того, Это Мероприятие Формирует Новое Определение Современной Конструкции Мечети В Аммане В Современную Эпоху; То, Что Обогащает Это Понятие Мечеть Представляет Официальных Государственных Мечеть Архитектурный Стиль Иордания.

Обобщая Историко-Архивные Исследования, А Также Данные О Сохранившихся На Сегодняшний День Мечетях, Можно Сказать, Что На Территории Иордании Объемно-Пространственное Решение Мечетей Было Представлено В Трех Типах:

- С Минаретом На Крыше;

- $\quad$ С Минаретом Над Входом;

- $\quad$ С Примыкающим Объемом Минарета.

Первый Тип Мечетей «С Минаретом На Крыше» Был Распространен Еще В Период Казанского Ханства (Рис. 3).

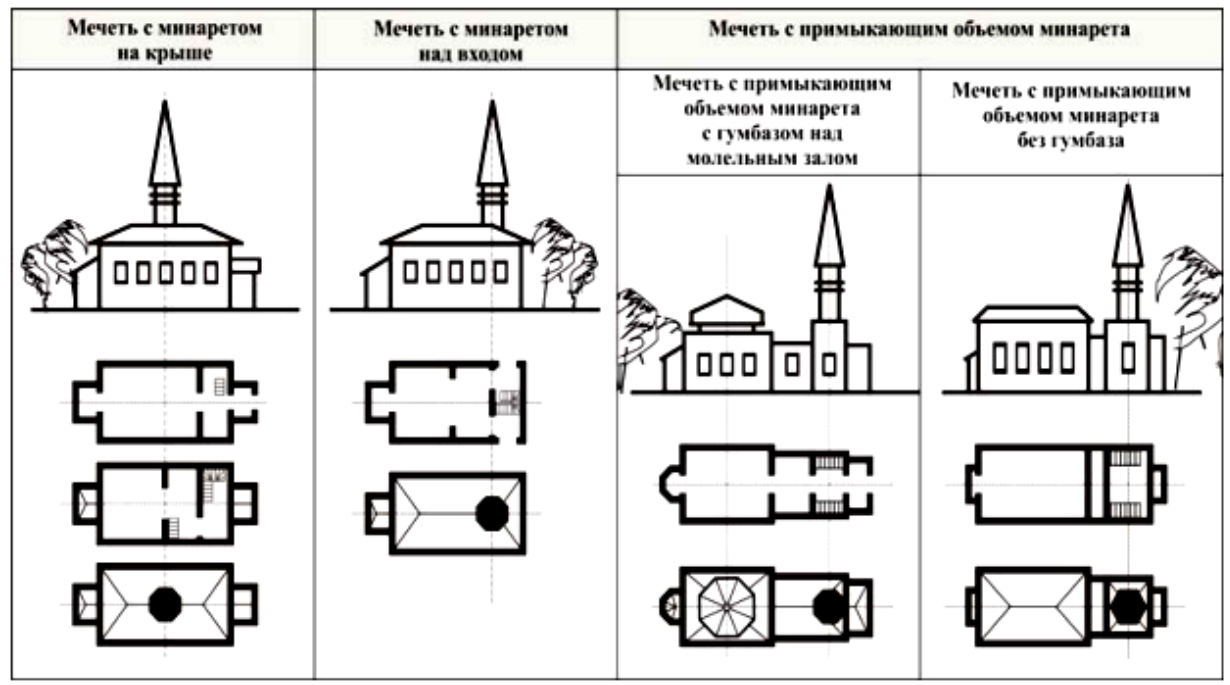

Рис. 3 - Типология Мечетей Суитов На Территории Иордании

В Конструктивном Решении Он Представлял Собой Сруб С Балочным Перекрытием И Скатной Крышей. Такое Решение Было Обусловлено, В Первую Очередь, Выбором Строительного Материала (Мечети Этого Типа Чаще Всего Возводили Из Дерева, Хотя Они Могли Быть Вы-Строены И Из Кирпича)

Объемно-Планировочная Композиция Состояла Из Прямоугольного В Плане Одно-, Двухэтажного Строения С Двускатной Крышей, Ориентированного По Оси Север-Юг. Стоит Отметить, Что «Юг»- Понятие Не Географическое, А Условное. Под Ним Заключается Расположение Оси Мечети По Направлению К Каабе - Святыне Ислама, Расположенной В Г. Мекке. Таким Образом, На Территории Томской Губернии Мечети В Основном Были Ориентированы На Юго-Запад. Михраб Был Расположен С Южного Торца, А Крышу Прорезал Восьмигранный (Реже - Цилиндрический) Минарет, Завершенный Пирамидальным Или Коническим Шатром [1, С. 23]. Располагался Минарет По Продольной Оси Над Геометрическим Центром Здания И Представлял Собой Двух-Трехъярусную Башню С Внутренней Площадкой Азанчи, Которая Была Застеклена И Могла Быть Обнесена Галереей. Конструктивное Решение Опорной Части Минарета Зависело От Выбора Строительного Материала. В Случае, Если Минарет Был Каменный, Он Опирался На Толстую Поперечную Стену, Разделявшую Мечеть На Ритуальную И Вестибюльную Зоны; Если Деревянный, То Крепился К Стропилам И Балкам Перекрытия [7].

Ко Второму Типу Относятся Мечети С Минаретом Над Входом. Минарет Расположен На Продольной Оси Здания, Над Капитальной Стеной, Разделя-Ющей Молельный Зал И Вестибюль. Башня Минарета Сильно Сдвинута К Входу И Находится На Коньке Крыши.

К Третьему Типу Мечетей (С Примыкающим Объемом Минарета). Отличительной Чертой Данного Типа Является То, Что Объем Минарета, Расположенного Также По Продольной Оси, Пристроен К Основному Объему Здания. Основной Объем Перекрывала Вальмовая Крыша Или Же Венчал Большой Купол-Гумбаз. Михраб Выделялся Отдельным Объемом Со Стороны Южного Торца Здания [5, С. 33]. 
Таким Образом, Мечети По Объемно-Пространственному Решению Они Были Трех Типов - С Минаретом На Крыше, С Минаретом Над Входом И С Приставным Объемом Минарета. Специфика Рассмотренных Мечетей Также Заключается И В Схожести С Русскими Православными Храмами, Особенно Это Характерно Для Такого Типа, Как Мечеть С Примыкающим Объемом Минарета. Расположение Башни Минарета И Гумбаза По Продольной Оси Схоже С Размещением Колокольни И Купола В Русской Церковной Архитектуре. Выделение Объема Михраба И Прямоугольные Очертания Молельного Зала, А Также Зонирование На Вестибюльную И Ритуальную Зоны Делают План Мечети Идентичным Плану Православного Храма Корабельного Типа. В Тематике Декоративных Украшений, Например В Орнаменте Пропиленной Или Накладной Резьбы Наличников, Фриза И Карниза, Использованы Характерные Для Деревянной Жилой Архитектуры Иордании Мотивы И Элементы.

\section{ЛИТЕРАТУРА:}

[1] Всеобщая История Архитектуры : В 12 Т. / Н. В. Баранов (Гл. Ред.). - М. : Стройиздат. - Т. 8 : Архитектура Стран Средиземноморья. Африки И Азии VI-XIX Вв. / Ю. С. Яралов (Отв. Ред.). 1969. - $490 \mathrm{C}$.

[2] Вейс Г. История Цивилизации: Архитектура, Вооружение, Одежда, Утварь: Иллюстрированная Энциклопедия В 3-X Томах. «Темные Века», «Средневековье». IV-XIV Вв. Т.II. М.: ЭКСМОПРЕСС, 1998. С 147-148.

[3] Гаврилюк Н.А. Тимченко Н.П. Ранние Культовые Памятники Столицы Крымского Ханства. V Научные Чтения Памяти У. Боданинского: Тезисы Докладов И Сообщений Международной Научной Конференции (Бахчисарай, 23-27 Октября 2013 Г.). Симферополь: Антиква, 2013. С. 25.

[4] Гаврилюк Н.А., Ибрагимова А.М. Тюрбе Хана Хаджи Герая (По Материалам Археологических Исследований 2003-2008 Гг.). Киев- Запорожье: Дикое Поле, 2010. 176 С.

[5] Кононенко Е. И. Анатолийские Мечети Великих Сельджуков: Архитектурные И Политические Ориентиры // Искусствознание. 2015. № 3-4.

[6] Моццати, Л. Исламское Искусство / JI. Моццати: Пер. С Итал. С. В. Зоновой. - М. : Арт Родник. 2012. - 388 C.

[7] Пиотровский М.M. Язык Мусульманского Искусства [Электронный Ресурс] - Режим Доступа: Http://Www.Tatmir.Ru/Passport.Shtml (Дата Обращения 15.05.2016)

\section{LITERATURE:}

[1] General History Of Architecture In 12 Volumes / N. V. Baranov (Ed.). - M. : Stroyizdat. - Vol. 8 : The Architecture Of Mediterranean Countries. Africa And Asia VI-XIX Centuries / Y. S. Aralov (Resp. Ed.). - 1969. - $490 \mathrm{P}$.

[2] Weiss G. The History Of Civilization: Architecture, Weapons, Clothing, Utensils: An Illustrated Encyclopedia In 3 Volumes. The "Dark Ages", "Medieval". IV-XIV Centuries. Vol. II. M.: EKSMOPRESS, 1998. With 147-148.

[3] Gavrilyuk N.. Timchenko N. P. The Early Religious Monuments Of The Capital Of The Crimean Khanate. V Scientific Readings In Memory Of W. Bodaninskomu: Abstracts And Reports Of International Scientific Conference (Yalta, 23-27 October, 2013). Simferopol: Antiqua, 2013. P.25.

[4] Gavrilyuk N. A. Ibragimov A. M. The Tomb Of Khan Haji Giray (On Materials Of Archaeological Research, 2003-2008). Kiev - Zaporozhye: Wild Pitch, 2010. 176 P.

[5] Kononenko E. I. Anatolian Mosques Of The Great Seljuks: Architecture And Political Landmarks // Art History. 2015. No. 3-4.

[6] Mozzati, L. Islamic Art / JI. Mozzati: Per. S Ital. S. V. Zonov. - M. : Art Spring. 2012. - 388 P.

[7] Piotrovsky M. M. The Language Of Islamic Art [Electronic Resource] - Mode Of Access: Http://Www.Tatmir.Ru/Passport.Shtml (Accessed 15.05.2016) 